\title{
Nitric Oxide Production Contributes to the Angiogenic Properties of Vascular Endothelial Growth Factor in Human Endothelial Cells
}

\author{
Andreas Papapetropoulos, ${ }^{\star}$ Guillermo García-Cardeña, ${ }^{*}$ Joseph A. Madri, ${ }^{\ddagger}$ and William C. Sessa* \\ $*$ Department of Pharmacology and Molecular Cardiobiology Division, Boyer Center for Molecular Medicine, ${ }^{\ddagger}$ Departments of \\ Pathology \& Biology, Yale University School of Medicine, New Haven, Connecticut 06536-0812
}

\begin{abstract}
Vascular endothelial growth factor (VEGF) is a regulator of vasculogenesis and angiogenesis. To investigate the role of nitric oxide (NO) in VEGF-induced proliferation and in vitro angiogenesis, human umbilical vein endothelial cells (HUVEC) were used. VEGF stimulated the growth of HUVEC in an NO-dependent manner. In addition, VEGF promoted the NO-dependent formation of network-like structures in HUVEC cultured in three dimensional (3D) collagen gels. Exposure of cells to VEGF led to a concentrationdependent increase in cGMP levels, an indicator of NO production, that was inhibited by nitro-L-arginine methyl ester. VEGF-stimulated NO production required activation of tyrosine kinases and increases in intracellular calcium, since tyrosine kinase inhibitors and calcium chelators attenuated VEGF-induced NO release. Moreover, two chemically distinct phosphoinositide 3 kinase (PI-3K) inhibitors attenuated NO release after VEGF stimulation. In addition, HUVEC incubated with VEGF for $24 \mathrm{~h}$ showed an increase in the amount of endothelial NO synthase (eNOS) protein and the release of NO. In summary, both short- and long-term exposure of human EC to VEGF stimulates the release of biologically active NO. While long-term exposure increases eNOS protein levels, short-term stimulation with VEGF promotes NO release through mechanisms involving tyrosine and PI-3K kinases, suggesting that NO mediates aspects of VEGF signaling required for EC proliferation and organization in vitro. (J. Clin. Invest. 1997. 100:3131-3139.) Key words: vascular endothelial growth factor - endothelium • nitric oxide $\bullet$ angiogenesis $\bullet$ cGMP
\end{abstract}

\section{Introduction}

Vascular endothelial growth factor (VEGF), ${ }^{1}$ a soluble angiogenic factor produced by many tumor and normal cells, is a 46-kD dimeric glycoprotein with similarity to platelet-derived growth factor (1-3). VEGF is secreted in four different forms that arise from alternative splicing of the VEGF primary tran-

Address correspondence to William C. Sessa, Yale University School of Medicine, Boyer Center for Molecular Medicine, 295 Congress Avenue, New Haven, CT 06536-0812. Phone: 203-737-2291; FAX: 203-737-2290.

Received for publication 6 June 1997 and accepted in revised form 7 October 1997.

J. Clin. Invest.

(C) The American Society for Clinical Investigation, Inc. 0021-9738/97/12/3131/09 \$2.00

Volume 100, Number 12, December 1997, 3131-3139

http://www.jci.org script $(3,4)$. All four peptides are biologically active, but differ in their physicochemical properties as well as their ability to bind heparin (2). $\mathrm{VEGF}_{165}$ is the most abundant of the four isoforms in vivo and is commonly used in studies investigating the biological effects of VEGF (3).

VEGF selectively stimulates endothelial cells by binding to cell surface receptors that possess intrinsic tyrosine kinase activity. Two such receptors, VEGFR-1 (also known as Flt-1) and VEGFR-2 (also known as Flk-1/KDR) have been reported on endothelial cells $(5,6)$. Outside the endothelium, monocytes, uterine smooth muscle, and pancreatic epithelial cells are the only cells reported to express functional VEGF receptors (7-9). The distribution of VEGF receptors suggests that VEGF is an important regulator of endothelial cell development and function. Indeed, transgenic animals with a null mutation for the VEGF gene, VEGFR-1 or VEGFR-2 exhibit embryonic lethality, characterized by absent or delayed endothelial cell differentiation and impaired vasculogenesis and angiogenesis (10-13).

Besides its involvement in vascular development, VEGF has been demonstrated to play a key role in both physiologic and tumor angiogenesis in adult mammals $(3,4,14)$. Additional biological actions of VEGF in adult organisms have been documented and include increased vascular permeability $(1,15)$ and vasodilation that is accompanied by a decrease in mean arterial pressure and tachycardia $(16,17)$. Recently, it was demonstrated that vasodilation and increased vascular permeability are inhibited by nitric oxide synthase inhibitors (15-17). Brock et al. (18), demonstrated that VEGF increases cytosolic calcium which is known to promote calmodulin binding on the endothelial isoform of nitric oxide synthase (NOS) and stimulate NO production (19). More recently, VEGF was shown to increase NO release in bovine, rabbit, and human endothelial cells $(20,21)$. In vitro, VEGF is a potent and selective mitogen for endothelial cells $(2,4)$. The mitogenic action of VEGF on bovine microvascular endothelial cells is NO mediated since nitric oxide synthase inhibitors block the VEGF-induced proliferation (20). Although both VEGF and NO-stimulating agents (substance $\mathrm{P}$, endothelin) promote endothelial cell migration $(22,23)$, it is unknown whether NO contributes to the chemotactic effects of VEGF.

Several reports have implicated NO in the angiogenic process $(22,24-26)$. Using an in vitro system, we have recently demonstrated that nitric oxide promotes TGF- $\beta 1$-driven capillary organization in three dimensional (3D) cultures (27). The aim of the present study was to determine if NO mediates the angiogenic properties of VEGF in human cells by affecting

1. Abbreviations used in this paper: CMZ, calmidazolium; CTL, control; eNOS, endothelial nitric oxide synthase; HUVEC, human umbilical vein endothelial cells; IBMX, isobutylmethylxanthine; L-NAME, nitro-L-arginine methylester; P1-3K, phosphoinositide-3 kinase; sGC, soluble guanylate cyclase; VEGF, vascular EGF. 
proliferation and/or organization of human umbilical vein endothelial cells (HUVEC) and to investigate the mechanism of VEGF-induced NO production.

\section{Methods}

Cell isolation and culture. Human endothelial cells were isolated from umbilical veins and cultured as previously described (28) on gelatin-coated tissue culture flasks in M199 containing 20\% FBS, $50 \mu \mathrm{g} / \mathrm{ml}$ EC growth supplement (ECGS, a commercial preparation that contains mainly fibroblast growth factor), $100 \mu \mathrm{g} / \mathrm{ml}$ porcine heparin, 10 $\mathrm{U} / \mathrm{ml}$ penicillin, and $100 \mu \mathrm{g} / \mathrm{ml}$ streptomycin. Two to three individual donors were pooled at passage one and used up to passage four. Cultures had typical cobblestone morphology and stained uniformly for von Willebrand factor, as assessed by indirect immunofluoresence.

Cell proliferation assays. HUVEC were seeded on rat tail type I collagen coated wells at 6,000 cells $/ \mathrm{cm}^{2}$ in complete growth medium and allowed to attach for 3-4 h. Medium was then replaced with fresh medium (M199 supplemented with 20\% FBS and antibiotics, not containing ECGS) with or without L-nitroarginine methylester (L-NAME) $(5 \mathrm{mM})$. After $30 \mathrm{~min}$ ECGS or VEGF $(50 \mathrm{ng} / \mathrm{ml})$ was added to the cultures. Cells were allowed to proliferate for $48 \mathrm{~h}$, trypsinized, and counted in a Coulter counter (Coulter Immunology, Hialeah, FL).

In vitro angiogenesis assay. 3D cultures were established as described with minor modifications (29). Rat tail type I collagen was mixed with $10 \times$ Earle's balanced salt solution and neutralized with $1 \mathrm{~N}$ $\mathrm{NaOH}$. HUVEC were added immediately to achieve a final concentration of $2 \times 10^{6}$ cells $/ \mathrm{ml}$ collagen (final collagen concentration was 2 $\mathrm{mg} / \mathrm{ml})$. Drops $(0.1 \mathrm{ml}$ each) of the cell/collagen mixture were added to tissue culture dishes, placed for $10 \mathrm{~min}$ in a humidified incubator at $37^{\circ} \mathrm{C}$, and allowed to gel for $10 \mathrm{~min}$. Growth medium was then added to each dish. Cultures were preincubated for $30 \mathrm{~min}$ with vehicle or L-NAME ( $5 \mathrm{mM})$ before being exposed to VEGF $(25 \mathrm{ng} / \mathrm{ml})$. VEGF was readded to the cultures every $12 \mathrm{~h}$. HUVEC were allowed to form tube-like structures for 1 or $2 \mathrm{~d}$. To evaluate tube formation in $3 \mathrm{D}$ cultures, cells were photographed and total network length (defined as an elongation of cells into tube-like structures typically seen in $3 \mathrm{D}$ cultures) was quantified in two to three fields per experiment using the National Institutes of Health (NIH)-Image program.

Determination of cGMP accumulation. HUVEC were cultured in 24-multiwell plates and used at confluence to determine cGMP accumulation as previously described (30). Briefly, cultures were washed with HBSS to remove traces of serum and incubated with the test compounds (DMSO as a vehicle up to $0.25 \%$, BAPTA/AM, calmidazolium, genistein, geldanamycin, LY 294002, or wortmannin) for 45 min. After the pretreatment period, $1 \mathrm{mM}$ isobutylmethylxanthine (IBMX) was added to inhibit the phosphodiesterases (5 min incubation). Nitric oxide production from HUVEC in response to VEGF was then assessed by the intracellular accumulation of cGMP over a 15 -min period. HBSS was then aspirated and $250 \mu \mathrm{l}$ of $0.1 \mathrm{~N} \mathrm{HCl}$ were added to each well to stop enzymatic reactions and to extract cGMP. 30 min later, the $\mathrm{HCl}$ extract was collected and stored until analyzed by RIA. To normalize cGMP values, protein content in each well was measured by the Bradford method after solubilization of the protein with $1 \mathrm{~N} \mathrm{NaOH}$. To determine the effect of long-term exposure of VEGF on NO production, HUVEC were treated for $24 \mathrm{~h}$ with $20 \mathrm{ng} / \mathrm{ml}$ VEGF. They were then washed with HBSS and incubated with $1 \mathrm{mM}$ IBMX in the presence or absence of ionomycin $(1 \mu \mathrm{M})$. cGMP was extracted and processed as described above.

Calcium measurements. All calcium measurements were performed on an ACAS 570 Interactive Laser Cytometer using a 488-nm argon source (Meridian, Inc., East Lansing, MI). $\left[\mathrm{Ca}^{2+}\right]$ was followed by using the fluorescent calcium probe fluo-3. HUVEC were loaded for $45 \mathrm{~min}$ with $2 \mu \mathrm{M}$ fluo-3/AM, using $0.5 \%$ pluronic acid at room temperature in the presence of vehicle (DMSO, $0.25 \%$ ) or the test compound (BAPTA/AM $12.5 \mu \mathrm{M}$, genistein $100 \mu \mathrm{M})$. They were then washed twice and placed in Krebs-Ringer-Hepes (KRH) (125 m M NaCl,
$5 \mathrm{mM} \mathrm{KCl}, 1 \mathrm{mM} \mathrm{KH}_{2} \mathrm{PO}_{4}, 1 \mathrm{mM} \mathrm{MgSO}{ }_{4}, 2 \mathrm{mM} \mathrm{CaCl}_{2}, 25 \mathrm{mM}$ Hepes, $6 \mathrm{mM}$ glucose). Plates were placed onto the stage of the ACAS 570 and visualized with an integrated, inverted microscope under phase contrast to select an appropriate field. After the addition of VEGF (20 $\mathrm{ng} / \mathrm{ml}$ ), repeated laser excitation of a field was performed with continuous recording of the fluorescent data. Fluorescent intensity curves were generated for individual cells using the kinetics software data analysis program available with the ACAS. A value of 1 was assigned to the fluorescence for each individual cell before stimulation with an agonist; all subsequent values are presented as a ratio of the observed fluorescence over the initial fluorescence (normalized fluorescence).

Immunoprecipitations and Western blotting. HUVEC were serum starved for $18 \mathrm{~h}$ in medium containing $2 \%$ bovine serum albumin. VEGF $(40 \mu \mathrm{g} / \mathrm{ml})$ was then added to the cells for an additional $24 \mathrm{~h}$. Cells were washed with phosphate buffered saline and lysed in a modified RIPA buffer (100 mM Tris-HCl, $50 \mathrm{mM} \mathrm{NaCl}, \mathrm{pH} 7.4,1 \%$ $\mathrm{vol} / \mathrm{vol}$ Nonidet P-40, $10 \mu \mathrm{g} / \mathrm{ml}$ aprotinin, and $10 \mu \mathrm{g} / \mathrm{ml}$ leupeptin). Lysates were then dounce homogenized and insoluble material pelleted by centrifugation $\left(12,000 \mathrm{~g}\right.$ for $10 \mathrm{~min}$ at $\left.4^{\circ} \mathrm{C}\right)$. Protein was determined by the Lowry method and $500 \mu \mathrm{g}$ of protein from each group (control or VEGF treated cells) were precleared. Lysates were then incubated for $2 \mathrm{~h}$ with an anti-endothelial NOS (eNOS) monoclonal antibody $(\mathrm{mAb})$ at $4^{\circ} \mathrm{C}$, protein A-Sepharose was added and incubated for an additional $1 \mathrm{~h}$. The immune complexes were washed three times with RIPA buffer and boiled in SDS-PAGE sample buffer for $5 \mathrm{~min}$. Immunoprecipitated samples were separated by SDSPAGE in a $7.5 \%$ gel followed by overnight transfer of the proteins to nitrocellulose membranes. Membranes were blocked with $0.1 \%$ Tween-20 in Tris-buffered saline containing 5\% nonfat dry milk for $2 \mathrm{~h}$ at room temperature, incubated with a anti-eNOS $\mathrm{mAb}$ for an additional $2 \mathrm{~h}$ and washed extensively. They were then incubated with a horseradish peroxidase-conjugated goat anti-mouse $\mathrm{Ab}$ for $30 \mathrm{~min}$ before being developed with the enhanced chemiluminescence substrate (ECL).

Data analysis and statistics. Data are presented as means \pm SEM or as percentage of control of the indicated number of observations. Statistical comparisons between groups were performed using the Student's $t$ test or one-way ANOVA followed by a post hoc test (Neuman-Keuls or Dunnett's), as appropriate. Differences among means were considered significant when $P<0.05$.

Materials. Tissue culture plasticware, rat tail type I collagen, human recombinant vascular endothelial growth factor $\left(\mathrm{VEGF}_{165}\right)$, and endothelial cell growth supplement were from Collaborative Biomedical Products (Bedford, MA). Growth medium, fetal calf serum, and transforming growth factor $\beta 1$ were purchased from GIBCO/ BRL (Grand Island, NY). BAPTA/AM, calmidazolium, genistein, geldanamycin, LY 294002, and wortmannin were obtained from Calbiochem (San Diego, CA). Protein A Sepharose was obtained from Pharmacia Fine Chemicals (Piscataway, NJ). The anti-eNOS monoclonal antibody was obtained from Transduction Labs (Lexington, $\mathrm{KY}$ ). The ECL detection system and the horseradish peroxidase conjugated anti-rabbit antibody was obtained from Amersham Life Sciences (Arlington Heights, IL). Nitrocellulose membranes were purchased from Gelman Sciences (Ann Arbor, MI). X-ray film was obtained from Eastman Kodak Co. (Rochester, NY). The ${ }^{125}$ I-cGMP radioimmunoassay kit was purchased from Biomedical Technologies Inc (Stoughton, MA). All other chemicals including penicillin, streptomycin, bovine serum albumin, NP-40, PMSF, aprotinin, EDTA, L-NAME, ionomycin, and others were purchased from Sigma Chemical Co. (St. Louis, MO).

\section{Results}

Effects of $\mathrm{NO}$ on endothelial cell proliferation. To investigate if NO contributes to the proliferative response of human endothelial cells to VEGF, proliferation assays were performed in the absence and presence of the NOS inhibitor L-NAME 


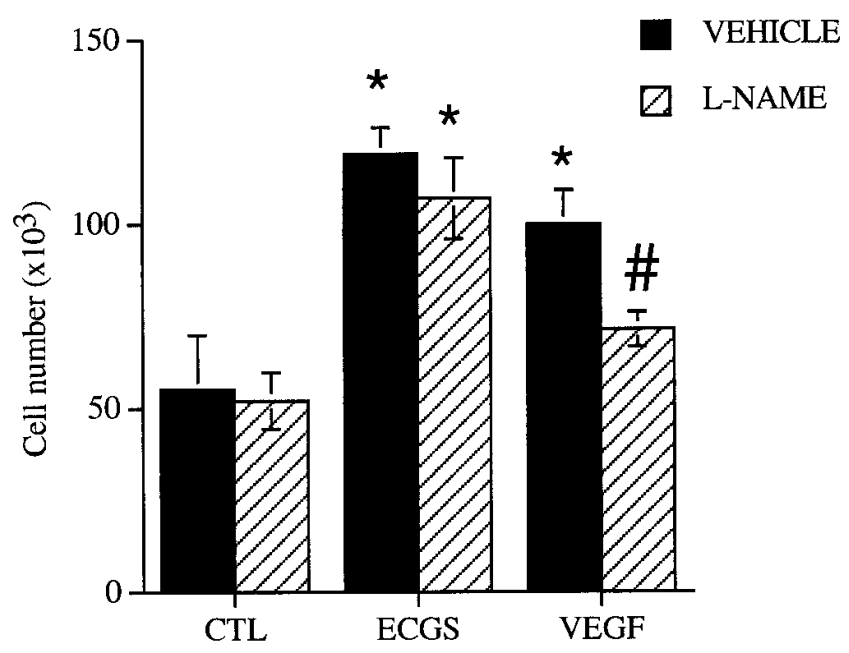

Figure 1. L-NAME inhibits VEGF-induced proliferation in HUVEC. HUVEC were seeded at 6,000 cells $/ \mathrm{cm}^{2}$ and allowed to attach for 3-4 $\mathrm{h}$ in complete growth medium. Medium was then changed to M199 supplemented with $20 \%$ FCS with or without L-NAME (5 mM). After $30 \mathrm{~min}$, cells were stimulated with ECGS $(50 \mu \mathrm{g} / \mathrm{ml})$ or VEGF $(50 \mathrm{ng} / \mathrm{ml})$ and allowed to proliferate for $48 \mathrm{~h}$. Cells were then trypsinized and counted using a Coulter counter. Means \pm SEM; $n=4$ wells; ${ }^{*} P<0.05$ from control (CTL), ${ }^{\#} P<0.05$ from vehicle.

( $5 \mathrm{mM}$ ). This high concentration of L-NAME was found to be necessary to completely block basal NO release in preliminary experiments. Since we were unable to consistently document basal release of NO in HUVEC (as assessed by L-NAMEinhibitable cGMP accumulation), a smooth muscle-HUVEC short-term coculture bioassay was used (31). Under these conditions, basal NO release as estimated by cGMP accumulation in the smooth muscle cells was $11.7 \pm 2.4,10.9 \pm 3.0$, and $2.3 \pm 1.2 \mathrm{pmol} / \mathrm{mg}$ protein $(n=3)$ for control, 1 , and $4 \mathrm{mM}$ L-NAME, respectively. The high concentration of this inhibitor (L-NAME) needed to block NO release is justified by the high concentration L-arginine $(400 \mu \mathrm{M})$ found in the culture medium.

Addition of ECGS $(50 \mu \mathrm{g} / \mathrm{ml})$ or VEGF $(50 \mathrm{ng} / \mathrm{ml})$ in the culture medium stimulated HUVEC proliferation over the course of $2 \mathrm{~d}$ (Fig.1). Inhibition of NO synthesis resulted in a $67 \%$ decrease in VEGF-stimulated proliferation without affecting the response to ECGS, suggesting that NO is an important mediator of VEGF signaling.

Effects of nitric oxide on VEGF-induced organization in vitro. HUVEC cultured in conventional two dimensional cultures exhibited a typical cobblestone morphology (Fig. $2 A$ ). In contrast, HUVEC seeded in 3D type I collagen gels and exposed to complete growth medium (containing ECGS), remained rounded or were minimally spread out (Fig. 2 B). On the other hand, cells exposed to complete growth medium supplemented with VEGF $(25 \mathrm{ng} / \mathrm{ml})$, exhibited a distinct phenotype assuming a more elongated shape (Fig. $2 C$ ). HUVEC stimulated with VEGF appeared to engage in the formation of a vascular network within $24-48$ h that subsequently disassembled. When control 3D cultures were grown for $7 \mathrm{~d}$ a large percentage of the cells underwent apoptosis (data not shown). It should be noted that not all of the cells in the 3D cultures participated in the formation of a vascular network and that vari- ability was observed between individual HUVEC cultures (pooled populations of two to three donors). The organization of HUVEC into cords and network structures in the presence of VEGF was inhibited by the addition of L-NAME to the medium (Fig. 2 D). Morphometric quantitation of the vessel-like structures in the 3D cultures revealed that L-NAME attenuated this response to VEGF by $58 \%$.

Short-term exposure to VEGF stimulates $N O$ production in human endothelial cells. Baseline cGMP levels in resting HUVEC are low (1.2 pmol/mg protein). Exposure of monolayers to $20 \mathrm{ng} / \mathrm{ml} \mathrm{VEGF}$ for $15 \mathrm{~min}$, in the presence of the phosphodiesterase inhibitor IBMX, led to a significant increase in cGMP levels (Fig. 3 A). This increase was inhibited by $100 \mu \mathrm{M}$ L-NAME, demonstrating that the rise in cGMP levels is due to the release of biologically active $\mathrm{NO}$ after stimulation with VEGF. A lower concentration of L-NAME is required to completely block NO release under these conditions since no arginine is present in the salt solution bathing the cells during the bioassay. The magnitude of the VEGF response was comparable to that of $1 \mu \mathrm{M}$ ionomycin, a nonreceptor agonist that maximally stimulates NO production. Unlike VEGF, incubation of HUVEC with TGF- $\beta 1$ (a known angiogenic factor, that has been used to promote in vitro angiogenesis by rat EC in this 3D culture model $[27,29])$ did not lead to an increase in NO production. The effect of VEGF on intracellular cGMP was concentration-dependent (Fig. $3 \mathrm{~B}$ ), with a steep rise in cGMP levels between 1 and $10 \mathrm{ng} / \mathrm{ml}$ VEGF.

To investigate the mechanism of the VEGF-induced NO release, cells were treated with the calcium chelating agent BAPTA/AM $(5 \mu \mathrm{M})$ or the calmodulin antagonist calmidazolium $(15 \mu \mathrm{M})$ for $45 \mathrm{~min}$ before stimulation with VEGF. Chelation of intracellular calcium and calmodulin antagonism, led to an inhibition of the VEGF-induced NO release (Fig. $4 A$ ). Since tyrosine phosphorylation events are an integral part of VEGF signalling, we investigated the effects of two chemically distinct protein tyrosine kinase inhibitors on VEGF-induced NO production. Pretreatment of monolayers with genistein $(100 \mu \mathrm{M})(32,33)$ or geldanamycin $(1 \mu \mathrm{g} / \mathrm{ml})$ attenuated cGMP accumulation in response to VEGF (Fig. $4 \mathrm{~B}$ ).

To investigate if exposure of EC to VEGF causes an increase in the concentration of intracellular calcium, cells were loaded with fluo-3/AM and stimulated with $20 \mathrm{ng} / \mathrm{ml}$ VEGF. Fig. 5 depicts calcium fluxes in individual cells. VEGF caused a delayed increase in $\left[\mathrm{Ca}^{2+}\right]_{i}$ compared to ionomycin or histamine. It should be noted that not all of the cells within a given field displayed calcium fluxes when exposed to VEGF. Incubation of the cultures with BAPTA/AM $(12.5 \mu \mathrm{M})$ completely blocked the VEGF-induced increase in $\left[\mathrm{Ca}^{2+}\right]_{\mathrm{i}}$. Interestingly, the tyrosine kinase inhibitor genistein did not inhibit the VEGF-induced calcium flux, but attenuated the VEGF-induced NO release (see above).

Stimulation of bovine aortic endothelial cells with VEGF has been shown to cause phosphorylation and activation of the phosphoinositide- 3 kinase (PI-3K) $(34,35)$. To determine if activation of PI-3K contributes to the increase of biologically active NO in response to VEGF, HUVEC were pretreated with two chemically different, specific inhibitors of PI-3K. Incubation of cells with LY294002 (LY; 10 or $100 \mu \mathrm{M})$ or wortmannin (WM; $500 \mathrm{nM}$ ) attenuated the VEGF-induced NO release (Fig. 6). It should be noted that none of the agents used to inhibit the production of VEGF-induced NO release affected the ability of soluble guanylate cyclase (sGC) to respond to ex- 

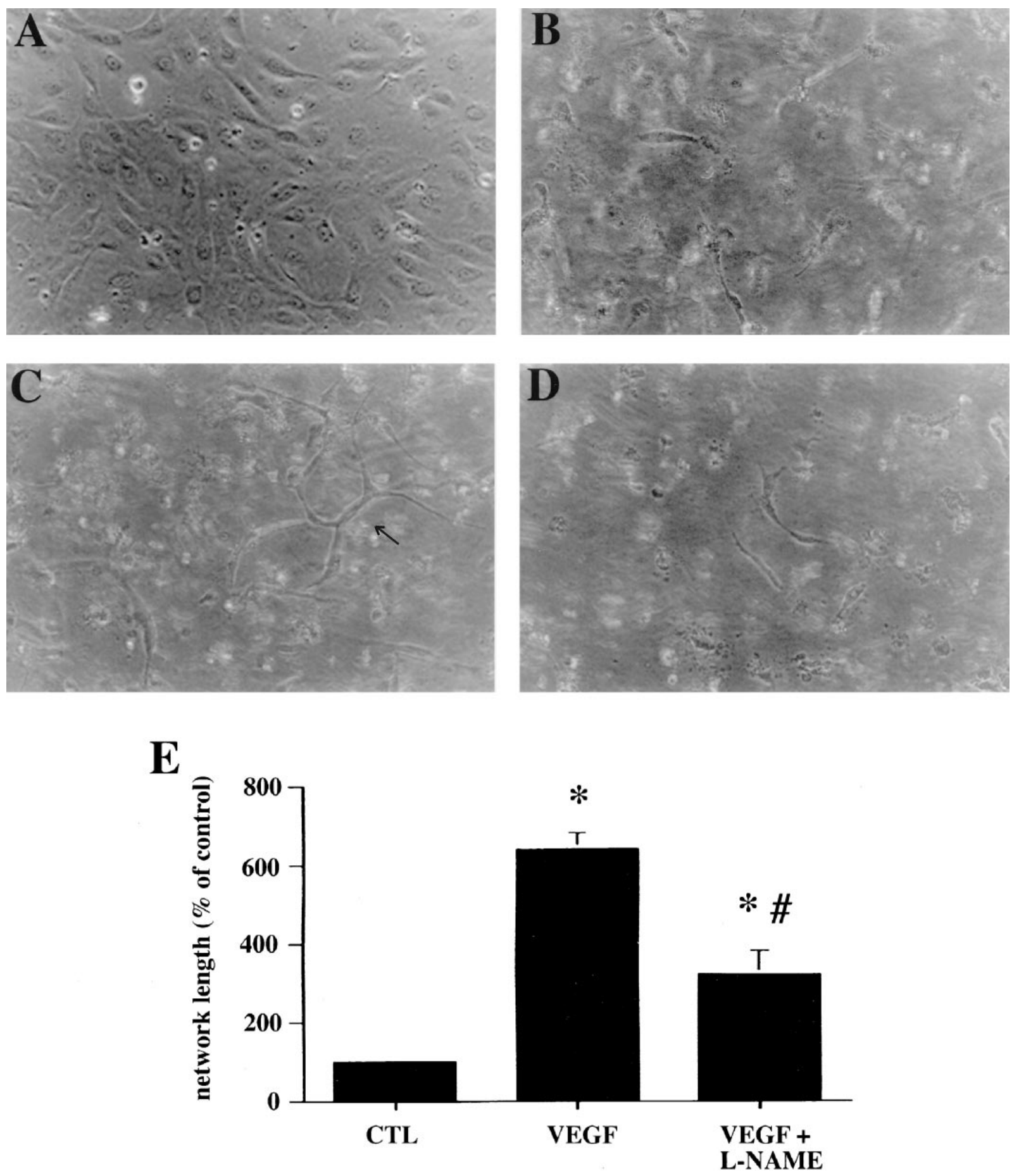

Figure 2. VEGF stimulates in vitro angiogenesis in 3D cultures of HUVEC in an NO-dependent manner. Whole mount view of HUVEC growing in $3 \mathrm{D}$ cultures. HUVEC were grown in $3 \mathrm{D}$ cultures $\left(2 \times 10^{6}\right.$ cells $/ \mathrm{ml}$ of collagen $)$ for $2 \mathrm{~d}$ in the absence or presence of VEGF $(25 \mathrm{ng} / \mathrm{ml})$ with or without L-NAME $(5 \mathrm{mM})$. Data are from a representative experiment. Similar results were obtained in at least three experiments. Magnification of 200. Arrow indicates the network structures that form with VEGF treatment. Morphometric quantification $(E)$ of the effect of L-NAME on VEGF-induced in vitro angiogenesis (two to three fields/experiment at a magnification of 200) was performed using the National Institutes of Health (NIH) image analysis program. Means \pm SEM. ${ }^{*} P<0.05$ from CTL, ${ }^{\sharp} P<0.05$ from VEGF.

ogenous NO. For these experiments, HUVEC were pretreated with the same concentration of the agents used to inhibit NO release (genistein, geldanamycin, LY294002, wortmannin, BAPTA, and CMZ) for $45 \mathrm{~min}$; sGC responsiveness to NO was then determined by stimulation with $100 \mu \mathrm{M}$ sodium nitroprusside (data not shown).

Long-term exposure to VEGF augments $N O$ production in human endothelial cells. To investigate the effects of long- 
A

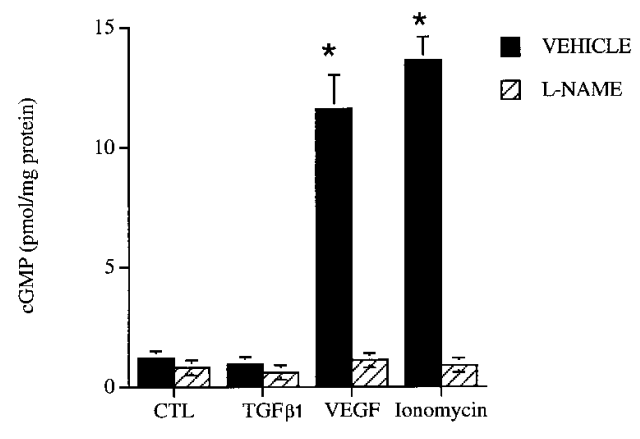

B

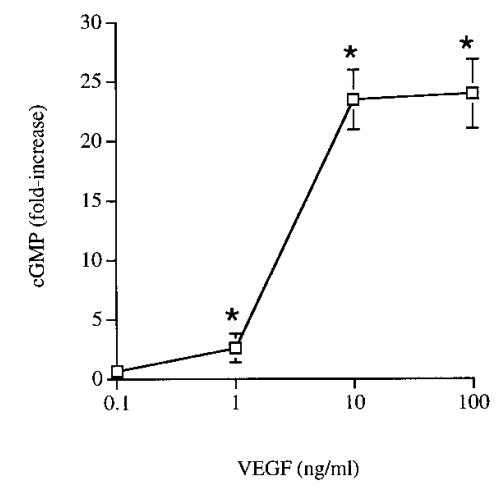

Figure 3. VEGF stimulates NO production in HUVEC. (A) Confluent HUVEC were washed with Hanks balanced salt solution and incubated with or without L-NAME $(100 \mu \mathrm{M})$ for $15 \mathrm{~min}$. They were then stimulated with transforming growth factor $\beta 1$ ( $5 \mathrm{ng} / \mathrm{ml})$, VEGF $(20 \mathrm{ng} / \mathrm{ml})$, or ionomycin $10 \mu \mathrm{M}$ in the presence of isobutylmethylxanthine $(1 \mathrm{mM})$ to inhibit phosphodiesterase activity, for an additional $15 \mathrm{~min}$. cGMP was extracted with $0.1 \mathrm{~N} \mathrm{HCl}$ and measured by radioimmunoassay. Means $\pm \mathrm{SEM} ; n=3$ wells; $* P<0.05$ from CTL. (B) HUVEC were washed with Hanks' balanced salt solution and stimulated with the indicated concentration of VEGF in the presence of isobutylmethylxanthine $(1 \mathrm{mM})$ for $15 \mathrm{~min}$. cGMP was then extracted with $0.1 \mathrm{~N} \mathrm{HCl}$ and measured by radioimmunoassay. Means \pm SEM; $n=4$ wells; ${ }^{*} P<0.05$ from CTL.

term treatment of human EC with VEGF, HUVEC were incubated with VEGF for $24 \mathrm{~h}$, lysed and equal amounts of protein from each group immunoprecipitated with an anti-eNOS mAb. Western blot analysis revealed that eNOS protein levels were increased (Fig. $7 A$ ). This increase was accompanied by an increase in the amount of NO released in response to ionomycin (Fig. 7 B).

\section{Discussion}

The aim of the present study was to determine if NO plays a role in different aspects (proliferation and organization) of the angiogenic response to VEGF and to investigate the mechanism mediating the release of NO in human endothelial cells exposed to VEGF. The major findings of the present study are that: $(a)$ NO mediates the VEGF-induced proliferation in human EC; (b) VEGF stimulates organization of human EC in $3 \mathrm{D}$ cultures in an NO-dependent manner; $(c)$ short-term expo-
A

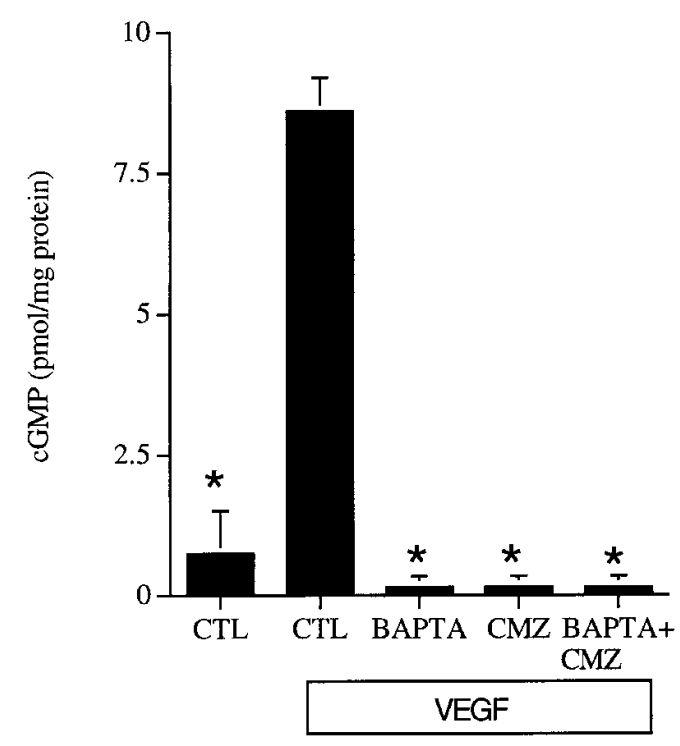

B

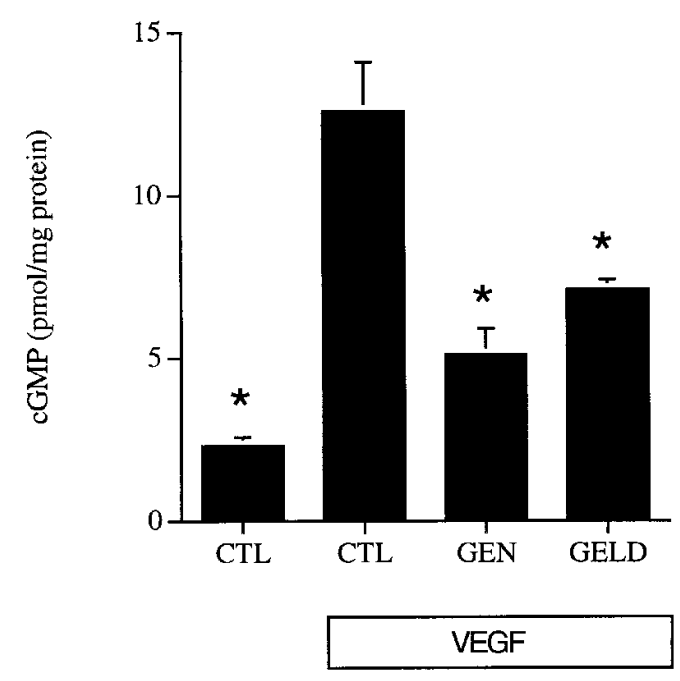

Figure 4. Tyrosine kinase inhibitors and calcium/calmodulin antagonists attenuate VEGF-stimulated NO production. (A) HUVEC monolayers were washed with HBSS and incubated with vehicle (DMSO), BAPTA/AM (BAPTA; $5 \mu \mathrm{M})$ or calmidazolium $(C M Z$; $15 \mu \mathrm{M})$ for $45 \mathrm{~min}$. Cells were then stimulated with VEGF $(20 \mathrm{ng} / \mathrm{ml})$ in the presence of isobutylmethylxanthine $(1 \mathrm{mM})$ to inhibit phosphodiesterase activity for an additional $15 \mathrm{~min}$. cGMP was extracted with $0.1 \mathrm{~N} \mathrm{HCl}$ and measured by radioimmunoassay. Means \pm SEM; $n=3$ wells; $* P<0.05$ from VEGF. $(B)$ HUVEC monolayers were washed with HBSS and incubated with vehicle (DMSO), genistein $(G E N ; 100 \mu \mathrm{M})$ or geldanamycin $(G E L D ; 1 \mu \mathrm{g} / \mathrm{ml})$ for $45 \mathrm{~min}$. Cells were then stimulated VEGF $(20 \mathrm{ng} / \mathrm{ml})$ in the presence of isobutylmethylxanthine $(1 \mathrm{mM})$ to inhibit phosphodiesterase activity, for an additional $15 \mathrm{~min}$. cGMP was extracted with $0.1 \mathrm{~N} \mathrm{HCl}$ and measured by radioimmunoassay. Means \pm SEM; $n=3$ wells; $* P<0.05$ from VEGF.

sure of HUVEC to VEGF causes increased NO production mediated by activation of tyrosine and phosphoinositide kinases; $(d)$ long-term exposure of human EC to VEGF leads to an increase in the protein levels of eNOS and the release of 

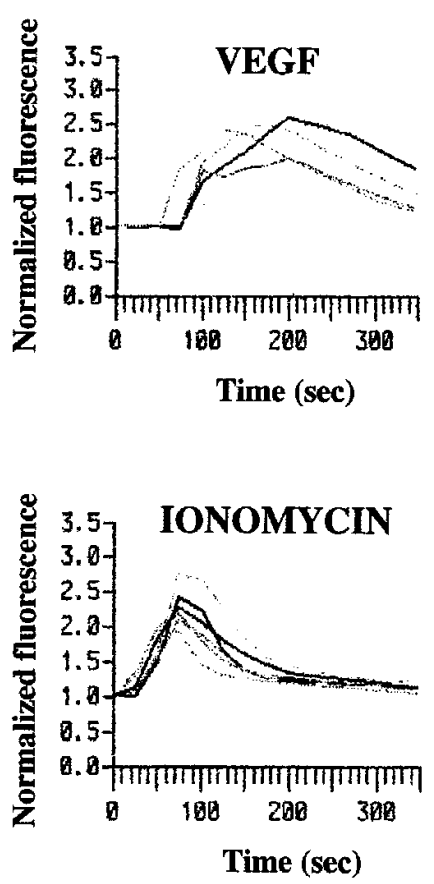
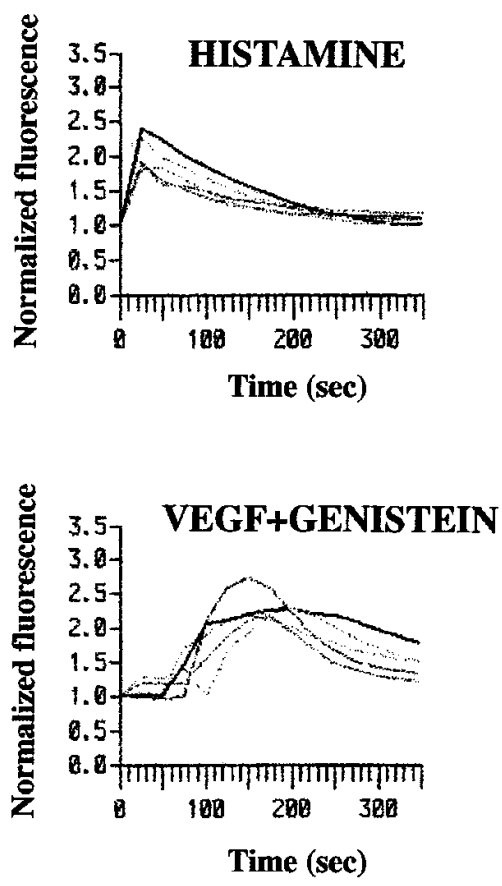

Figure 5. Exposure of HUVEC to VEGF leads to increases in intracellular calcium that are not attenuated by the protein tyrosine kinase inhibitor genistein. HUVEC were loaded with fluo-3 in the presence of vehicle (DMSO) or genistein $(100 \mu \mathrm{M})$ as described in the Methods section. Cells were then stimulated with VEGF $(20 \mathrm{ng} / \mathrm{ml})$, ionomycin $(1 \mu \mathrm{M})$ or histamine $(10 \mu \mathrm{M})$ and fluorescent signals, corresponding to free cytosolic calcium concentrations were recorded in real time.
NO. These data collectively suggest that the NO produced after VEGF stimulation is involved in VEGF signaling and mediates various aspects of its angiogenic properties and that VEGF augments eNOS expression and the stimulated production of NO. Recently, these in vitro findings were extended by the demonstration that VEGF-induced angiogenesis, in vivo, is significantly attenuated by NOS inhibition (36).

Angiogenesis, the process of new blood vessel formation from preexisting ones, is comprised of several discrete steps including dissolution of matrix, endothelial cell migration, proliferation and organization into a network structure, followed by lumen formation. NO has been implicated in all of the above mentioned processes in a manner consistent with a proangiogenic phenotype. Endogenously produced NO in response to substance $\mathrm{P}$ and VEGF stimulates EC growth in bovine cells $(20,22)$. In addition, $\mathrm{NO}$ released after endothelin $\mathrm{ET}_{\mathrm{B}}$ receptor activation promotes migration of HUVEC that is blocked

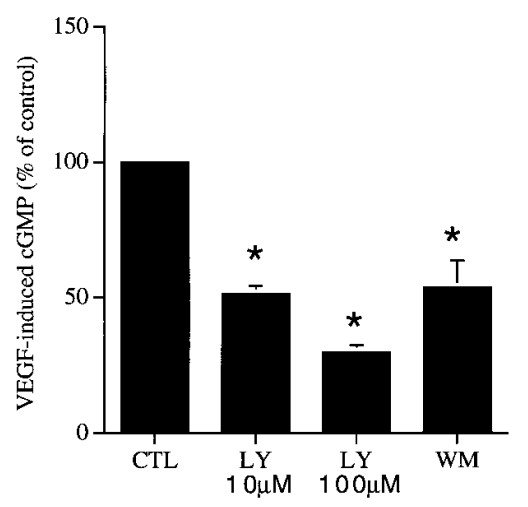

Figure 6. Inhibition of PI-3K attenuates the VEGF-induced NO release. HUVEC monolayers were washed with Hanks' balanced salt solution and incubated with vehicle (DMSO), wortmannin $(W M ; 500$ $\mathrm{nM})$, or LY294002 $(L Y ; 10$ or $100 \mu \mathrm{M})$ for $45 \mathrm{~min}$. Cells were then stimulated VEGF (20 $\mathrm{ng} / \mathrm{ml}$ ) in the presence of isobutylmethylxan-

thine $(1 \mathrm{mM})$ to inhibit phosphodiesterase activity, for an additional 15 min. cGMP was extracted with $0.1 \mathrm{~N} \mathrm{HCl}$ and measured by radioimmunoassay. Means \pm SEM; $n=3$ wells; $* P<0.05$ from CTL. by antisense oligonucleotides to eNOS (23). We have recently shown that NOS inhibitors attenuate TGF- $\beta 1$-induced angiogenesis in vitro (27). With the exception of the chick chorioallantoic membrane (24), NO is shown to promote angiogenesis in vivo: NOS inhibitors block neovascularization in response to substance $\mathrm{P}$ and monocyte-derived lipopolysaccharide-stimulated angiogenic activity in the cornea micropocket assay (22, $25)$, reduce flow in tumor associated neovasculature (37) and delay healing of gastric ulcers (38). Moreover, a human colon adenocarcinoma cell line, genetically engineered to produce NO, gave rise to larger, more vascularized tumors when injected in mice (26).

To determine if $\mathrm{NO}$ plays a role in the angiogenic response to VEGF, 3D cultures of HUVEC in type I collagen gels were established in the presence and absence of L-NAME. This in vitro model for angiogenesis has been used to evaluate responses of rat and bovine microvascular cells to VEGF, TGF$\beta 1$, basic fibroblast growth factor (bFGF), or combinations of these growth factors $(29,39)$. Montesano and Orci (40), demonstrated that PMA stimulates the formation of a vascular network by HUVEC in 3D collagen gels. Although the development of a tube-like network in response to VEGF was not as striking as that observed in response to PMA, HUVEC cultured in the presence of VEGF exhibited a greater degree of elongation and appeared to engage in a network formation more so than cells in control cultures. Morphometric quantification of this response confirmed the visual observation that NO mediates, in part, the VEGF response. Typically network formation in $3 \mathrm{D}$ culture is independent of proliferatiion and most likely reflects organization and stabilization of a complex endothelial cell phenotype, therefore the inhibition of network formation by L-NAME is unlikely due to inhibition of EC proliferation in $3 \mathrm{D}$ culture.

Since endothelial cell proliferation is an important aspect of angiogenesis, we investigated if NO mediates the proliferative effect of VEGF on human EC. HUVEC were allowed to 
A

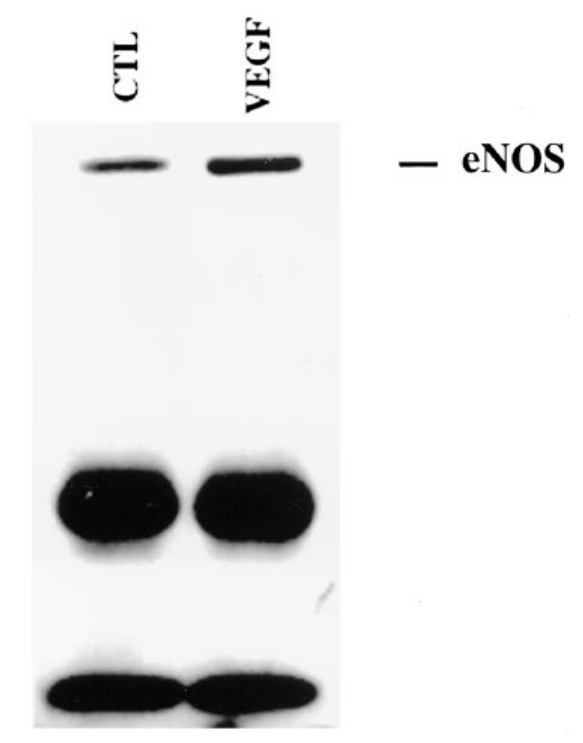

B

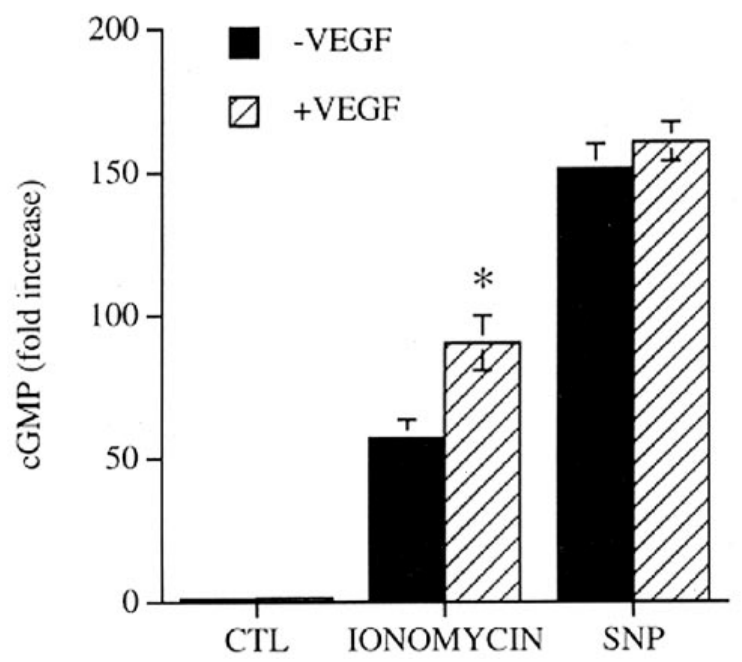

Figure 7. Long-term exposure to VEGF increases eNOS protein levels and NO release. $(A)$ HUVEC were treated with VEGF $(40 \mu \mathrm{g} / \mathrm{ml})$ for $24 \mathrm{~h}$. Cells were then washed with phosphate buffered saline and lysed. Equal amounts of protein $(500 \mu \mathrm{g})$ from each group were immunoprecipitated with anti eNOS mAb. Immune complexes were separated by SDS-PAGE, transferred to nylon membranes, and blotted with an anti-eNOS mAb. (B) HUVEC monolayers were treated with VEGF $(20 \mu \mathrm{g} / \mathrm{ml})$ for $24 \mathrm{~h}$. They were then washed with HBSS and stimulated with ionomycin $(1 \mu \mathrm{M})$ or SNP $(100 \mu \mathrm{M})$ in the presence of IBMX $(1 \mathrm{mM})$ for an additional $15 \mathrm{~min}$. cGMP was extracted with $0.1 \mathrm{~N} \mathrm{HCl}$ and measured by radioimmunoassay. Means \pm SEM; $n=3 ; * P<0.05$ from VEGF.

proliferate for $48 \mathrm{~h}$ with or without L-NAME in the presence of VEGF. Inhibition of NO production attenuated the VEGFstimulated proliferation in HUVEC, without affecting the response to ECGS. This observation is in agreement with previous reports that NOS inhibitors block the mitogenic effects of VEGF and substance $\mathrm{P}$ in bovine microvascular cells, without affecting bFGF migration and angiogenesis $(20,22)$.

$\mathrm{NO}$ is generated from the guanidino groups of $\mathrm{L}$-arginine in a reaction catalyzed by the enzyme nitric oxide synthase (NOS) $(19,41)$. Vascular endothelial cells constitutively express eNOS (type III NOS), but are also capable of generating large amounts of NO through the inducible NOS (type II or iNOS) pathway after cytokine stimulation $(19,42)$. HUVEC are a notable exception, since they are unable to express iNOS even when exposed to mixtures of cytokines. Interestingly, stimulation of HUVEC with cytokines results in increased NO production through eNOS, that is due to increased synthesis of tetrahydrobiopterin, a necessary cofactor for all NOS isoforms that is depleted in serially passaged HUVEC (28). NO synthesis in endothelial cells can be stimulated by mechanical forces (such as shear stress and cyclic strain) or after exposure to agonists (such as acetylcholine, bradykinin, and substance $\mathrm{P}$ among others) $(19,41)$. It was recently appreciated that short-term exposure of EC to growth factors, such as IGF-1 and insulin, augments NO production $(43,44)$. However, the mechanism of NO release caused by classic agonists has important differences with the mechanism by which mechanical forces or IGF-1 stimulate NO production in endothelial cells. The former, increase the intracellular calcium concentration that promotes calmodulin binding to eNOS leading to activation (19), while the latter utilize calcium-independent, tyrosine kinase mediated mechanisms to stimulate NO release (45). Here we show that VEGF caused a concentration-dependent increase in cGMP accumulation that was inhibited by L-NAME. Our results are in agreement with previous reports that VEGF stimulates NO production in bovine microvascular cells (20). van der Zee et al. (21), recently reported that exposure of HUVEC to VEGF causes accumulation of nitrite in the medium. In this case, nitrite accumulation increased up to $100 \mathrm{ng} / \mathrm{ml} \mathrm{VEGF}$, whereas in the present study VEGF-induced cGMP accumulation reached a plateau at a concentration that is one order of magnitude smaller. Since the capacity of sGC to produce cGMP is not a limiting factor under our experimental conditions (cGMP accumulation in response to SNP is greater than the cGMP levels at saturating VEGF concentrations), the greater amounts of nitrite released at higher VEGF concentrations do not represent biologically active NO. Exposure of EC to VEGF promotes superoxide anion formation (20), that may prevail at higher VEGF concentrations and inactivate part of the NO produced. Stimulation of HUVEC with TGF- $\beta 1$ another angiogenic cytokine, previously shown to promote capillary organization in the $3 \mathrm{D}$ cultures, failed to increase NO release. Longer exposures of EC to TGF- $\beta 1$ have been shown to lead to increased levels of eNOS protein and increased agonist induced NO release (46).

In agreement with previously published results (18), we observed that exposure of HUVEC to VEGF increased $\left[\mathrm{Ca}^{2+}\right]_{i}$. In addition, pretreatment of HUVEC with calcium chelators or the calmodulin antagonist calmidazolium, blocked the VEGF-induced NO release. Since calcium is required for the activity of some protein kinases and affects a number of phosphorylation/dephosphorylation events, it is unclear whether inhibition of NO production by BAPTA occurs at the level of eNOS or upstream.

Unlike many EC in culture, HUVEC retain their Flk-1 and Flt-1receptors $(47,48)$. Binding of VEGF to its receptors causes receptor dimerization and autophosphorylation on tyrosine residues (3). The presence of phosphotyrosine on the cytoplasmic tail of the receptor promotes interactions with proteins that contain the Src homology region 2 (SH2), a con- 
served sequence of $\sim 100$ amino acids (49). Several proteins that associate with the VEGF receptors have been identified including PI-3K, phospholipase C- $\gamma$ (PLC- $\gamma$ ), GTPase activating protein and the oncogenic adaptor protein $\mathrm{NcK}(34,35$, 50). PLC- $\gamma$ activation leads to increased formation of diacylglycerol and inositol 1,4,5 triphosphate $\left(\mathrm{IP}_{3}\right)$, increased intracellular calcium concentration, activation of protein kinase $\mathrm{C}$ and calcium/calmodulin kinases $(51,52)$. PI-3K on the other hand, leads to generation of phosphatidylinositol species phosphorylated at the D3 position of the inositol ring that serve as signaling molecules activating protein kinase $C$ and Akt $(53,54)$. To further investigate the mechanism by which VEGF causes NO release in human EC, pharmacologic inhibitors of tyrosine kinases and PI-3K were used. Inhibition of protein tyrosine kinases by two different agents (genistein, geldanamycin) attenuated the VEGF-induced NO release. Tyrosine kinase inhibitors have been shown to have varying effects on NO release; genistein blocked IGF-1-stimulated NO release in HUVEC and erbstatin A, a different tyrosine kinase inhibitor, attenuated acetylcholine-induced vasorelaxation $(44,45)$. On the other hand, genistein did not inhibit bradykinin-induced NO production in cultured bovine aortic EC or coronary arteriolar relaxations to substance $\mathrm{P}(55,56)$, suggesting that the involvement of tyrosine kinases in $\mathrm{NO}$ production is stimulus, vascular bed and/or species specific. It should be noted that tyrosine kinase inhibition attenuates tumor angiogenesis in vivo, as well as endothelial cell proliferation in vitro $(35,57)$. Previous studies have demonstrated the interdependence of tyrosine phosphorylation and calcium signalling in $\operatorname{EC}(32,58)$. To determine if the effects of genistein were mediated by a decrease in intracellular calcium, cells were loaded with fluo-3 in the presence and absence of genistein and stimulated with VEGF. In spite of reports that genistein blocks VEGF-induced tyrosine phosphorylation of PLC- $\gamma$ (34) we detected no inhibition of calcium mobilization in cells pretreated with genistein, suggesting that the decreased NO production seen in the presence of tyrosine kinase inhibitors is not due to inhibition of the calcium/calmodulin activation of eNOS. Perhaps genistein blocks a tyrosine kinase cascade that indirectly, through another serine kinase, may influence the phosphorylation of eNOS and subsequent activation by calcium and calmodulin.

VEGF-induced PI-3K phosphorylation or activation has been shown to occur in some, but not all cultured endothelial cells $(34,35,59)$. To investigate the involvement of a different signaling pathway in the VEGF-induced NO release, HUVEC were pretreated with the PI-3K inhibitors LY294002 or wortmannin. Both agents attenuated the release of $\mathrm{NO}$ in response to VEGF, suggesting that PI-3K activation mediates, at least in part, the response of VEGF. This is in agreement with previous observations that PI-3K inhibition blocks insulin and IGF-1-induced NO production in HUVEC (43). It is interesting to note that PI-3K activation influences several aspects of the angiogenic response. Wortmannin inhibits angiogenesis in the chick chorioallantoic membrane in vivo and lipid products of PI-3K increase cell motility $(60,61)$. It is, thus, tempting to speculate that the antiangiogenic effects of both tyrosine and PI-3K inhibitors are mediated through inhibition of NO synthesis. The exact mechanism by which PI-3K is involved in NO release is unknown. Several possibilities exist: PI-3K may be affecting (directly or through downstream signalling molecules such as Akt) the phosphorylation state of eNOS, or the PI-3K lipid products may be directly acting on eNOS. The latter seems unlikely since eNOS does not contain a pleckstrin homology domain required for most lipid-protein interactions. Alternatively, PI-3K inhibitors may be affecting eNOS localization, and thus optimal NO production $(62,63)$, as PI-3K is involved in vesicular trafficking $(53,64)$.

In summary, we have demonstrated that in human cells, NO production in response to short-term VEGF exposure is mediated by the activation of tyrosine kinases and PI-3K; longterm exposure to VEGF augments NO release through increased expression of the eNOS protein. Moreover, NO mediates a proliferative and angiogenic response to VEGF in vitro. These observations taken together with previous results that TGF- $\beta 1-$ driven capillary tube formation is sensitive to NO inhibition, suggest that NO may be an important modulator of growth factor signaling in endothelial cells.

\section{Acknowledgments}

The authors wish to thank Ms. Louise Benson and Gwendolyn Davis for assistance with the endothelial cell culture.

This work was supported by National Institutes of Health (NIH) grants R29-HL51948 and RO1-HL57665 and an American Heart Association (AHA) grant Connecticut Affiliate to W.C. Sessa, NIH grants RO1-HL28373 and PO1-DK38979 to J.A. Madri, and by the Patrick and Catherine Weldon Donaghue Medical Research Foundation Grant DF96-133 to A. Papapetropoulos. W.C. Sessa is an Established Investigator of the AHA.

\section{References}

1. Brown, L.F., M. Detmar, K. Claffey, J.A. Nagy, D. Feng, A.M. Dvorak, and H.F. Dvorak. 1997. Vascular permeability factor/vascular endothelial growth factor: a multifunctional angiogenic cytokine. Exs. 79:233-269.

2. Ferrara, N., K. Houck, L. Jakeman, and D.W. Leung. 1992. Molecular and biological properties of the vascular endothelial growth factor family of proteins. Endocr. Rev. 13:18-32.

3. Ferrara, N. 1996. Vascular endothelial growth factor. Eur. J. Cancer. 32A:2413-2422.

4. Thomas, K.A. 1996. Vascular endothelial growth factor, a potent and selective angiogenic agent. J. Biol. Chem. 271:603-606.

5. Terman, B.I., M. Dougher-Vermazen, M.E. Carrion, D. Dimitrov, D.C Armellino, D. Gospodarowicz, and P. Bohlen. 1992. Identification of the KDR tyrosine kinase as a receptor for vascular endothelial cell growth factor. Biochem. Biophys. Res. Commun. 187:1579-1586.

6. de Vries, C., J.A. Escobedo, H. Ueno, K. Houck, N. Ferrara, and L.T. Williams. 1992. The fms-like tyrosine kinase, a receptor for vascular endothelial growth factor. Science. 255:989-991.

7. Rooman, I., F. Schuit, and L. Bouwens. 1997. Effect of vascular endothelial growth factor on growth and differentiation of pancreatic ductal epithelium. Lab. Invest. 76:225-232.

8. Clauss, M., H. Weich, G. Breier, U. Knies, W. Rockl, J. Waltenberger, and W. Risau. 1996. The vascular endothelial growth factor receptor Flt-1 mediates biological activities. Implications for a functional role of placenta growth factor in monocyte activation and chemotaxis. J. Biol. Chem. 271:17629-17634.

9. Brown, L.F., M. Detmar, K. Tognazzi, G. Abu-Jawdeh, and M.L. IruelaArispe. 1997. Uterine smooth muscle cells express functional receptors (flt-1 and KDR) for vascular permeability factor/vascular endothelial growth factor. Lab. Invest. 76:245-255.

10. Fong, G.H., J. Rossant, M. Gertsenstein, and M.L. Breitman. 1995. Role of the Flt-1 receptor tyrosine kinase in regulating the assembly of vascular endothelium. Nature. 376:66-70.

11. Ferrara, N., K. Carver-Moore, H. Chen, M. Dowd, L. Lu, K.S. O'Shea, L. Powell-Braxton, K.J. Hillan, and M.W. Moore. 1996. Heterozygous embryonic lethality induced by targeted inactivation of the VEGF gene. Nature. 380: 439-442.

12. Carmeliet, P., V. Ferreira, G. Breier, S. Pollefeyt, L. Kieckens, M. Gertsenstein, M. Fahrig, A. Vandenhoeck, K. Harpal, C. Eberhardt, et al. 1996. Abnormal blood vessel development and lethality in embryos lacking a single VEGF allele. Nature. 380:435-439.

13. Shalaby, F., J. Rossant, T.P. Yamaguchi, M. Gertsenstein, X.F. Wu, M.L. Breitman, and A.C. Schuh. 1995. Failure of blood-island formation and vasculogenesis in Flk-1-deficient mice. Nature. 376:62-66.

14. Shibuya, M. 1995. Role of VEGF-flt receptor system in normal and tu- 
mor angiogenesis. Adv. Cancer Res. 67:281-316.

15. Wu, H.M., Q. Huang, Y. Yuan, and H.J. Granger. 1996. VEGF induces NO-dependent hyperpermeability in coronary venules. Am. J. Physiol. 271: H2735-H2739.

16. Yang, R., G.R. Thomas, S. Bunting, A. Ko, N. Ferrara, B. Keyt, J. Ross, and H. Jin. 1996. Effects of vascular endothelial growth factor on hemodynamics and cardiac performance. J. Cardiovasc. Pharmacol. 27:838-844.

17. Ku, D.D., J.K. Zaleski, S. Liu, and T.A. Brock. 1993. Vascular endothelial growth factor induces EDRF-dependent relaxation in coronary arteries. Am. J. Physiol. 265:H586-H592.

18. Brock, T.A., H.F. Dvorak, and D.R. Senger. 1991. Tumor-secreted vascular permeability factor increases cytosolic $\mathrm{Ca} 2+$ and von Willebrand factor release in human endothelial cells. Am. J. Pathol. 138:213-221.

19. Moncada, S., R.M. Palmer, and E.A. Higgs. 1991. Nitric oxide: physiology, pathophysiology, and pharmacology. Pharmacol. Rev. 43:109-142.

20. Morbidelli, L., C.H. Chang, J.G. Douglas, H.J. Granger, F. Ledda, and M. Ziche. 1996. Nitric oxide mediates mitogenic effect of VEGF on coronary venular endothelium. Am. J. Physiol. 270:H411-H415.

21. van der Zee, R., T. Murohara, Z. Luo, F. Zollmann, J. Passeri, C. Lekutat, and J.M. Isner. 1997. Vascular endothelial growth factor/vascular permeability factor augments nitric oxide release from quiescent rabbit and human vascular endothelium. Circulation. 95:1030-1037.

22. Ziche, M., L. Morbidelli, E. Masini, S. Amerini, H.J. Granger, C.A. Maggi, P. Geppetti, and F. Ledda. 1994. Nitric oxide mediates angiogenesis in vivo and endothelial cell growth and migration in vitro promoted by substance P. J. Clin. Invest. 94:2036-2044.

23. Noiri, E., Y. Hu, W.F. Bahou, C.R. Keese, I. Giaever, and M.S. Goligorsky. 1997. Permissive role of nitric oxide in endothelin-induced migration of endothelial cells. J. Biol. Chem. 272:1747-1752.

24. Pipili-Synetos, E., E. Sakkoula, G. Haralabopoulos, P. Andriopoulou, P. Peristeris, and M.E. Maragoudakis. 1994. Evidence that nitric oxide is an endogenous antiangiogenic mediator. Br. J. Pharmacol. 111:894-902.

25. Leibovich, S.J., P.J. Polverini, T.W. Fong, L.A. Harlow, and A.E. Koch. 1994. Production of angiogenic activity by human monocytes requires an L-arginine/nitric oxide-synthase-dependent effector mechanism. Proc. Natl. Acad. Sci. USA. 91:4190-4194.

26. Jenkins, D.C., I.G. Charles, L.L. Thomsen, D.W. Moss, L.S. Holmes, S.A. Baylis, P. Rhodes, K. Westmore, P.C. Emson, and S. Moncada. 1995. Roles of nitric oxide in tumor growth. Proc. Natl. Acad. Sci. USA. 92:43924396.

27. Papapetropoulos, A., K.M. Desai, R.D. Rudic, B. Mayer, R. Zhang, M.P. Ruiz-Torres, G. García-Cardeña, J.A. Madri, and W.C. Sessa. 1997. Nitric oxide synthase inhibitors attenuate transforming-growth-factor-beta1-stimulated capillary organization in vitro. Am. J. Pathol. 150:1835-1844.

28. Rosenkranz-Weiss, P., W.C. Sessa, S. Milstien, S. Kaufman, C.A. Watson, and J.S. Pober. 1994. Regulation of nitric oxide synthesis by proinflammatory cytokines in human umbilical vein endothelial cells. Elevations in tetrahydrobiopterin levels enhance endothelial nitric oxide synthase specific activity. $J$. Clin. Invest. 93:2236-2243.

29. Sankar, S., N. Mahooti-Brooks, L. Bensen, T.L. McCarthy, M. Centrella, and J.A. Madri. 1996. Modulation of transforming growth factor beta receptor levels on microvascular endothelial cells during in vitro angiogenesis. $J$. Clin. Invest. 97:1436-1446.

30. Papapetropoulos, A., A. Cziraki, J.W. Rubin, C.D. Stone, and J.D. Catravas. 1996. cGMP accumulation and gene expression of soluble guanylate cyclase in human vascular tissue. J. Cell. Physiol. 167:213-221.

31. Papapetropoulos, A., N. Marczin, M.D. Snead, C. Cheng, A. Milici, and J.D. Catravas. 1994. Smooth muscle cell responsiveness to nitrovasodilators in hypertensive and normotensive rats. Hypertension (Dallas). 23:476-484.

32. Fleming, I., B. Fisslthaler, and R. Busse. 1996. Interdependence of calcium signaling and protein tyrosine phosphorylation in human endothelial cells. J. Biol. Chem. 271:11009-11015.

33. Akiyama, T., J. Ishida, S. Nakagawa, H. Ogawara, S. Watanabe, N. Itoh, M. Shibuya, and Y. Fukami. 1987. Genistein, a specific inhibitor of tyrosinespecific protein kinases. J. Biol. Chem. 262:5592-5595.

34. Xia, P., L.P. Aiello, H. Ishii, Z.Y. Jiang, D.J. Park, G.S. Robinson, H. Takagi, W.P. Newsome, M.R. Jirousek, and G.L. King. 1996. Characterization of vascular endothelial growth factor's effect on the activation of protein kinase C, its isoforms, and endothelial cell growth. J. Clin. Invest. 98:2018-2026.

35. Guo, D., Q. Jia, H.Y. Song, R.S. Warren, and D.B. Donner. 1995. Vascular endothelial cell growth factor promotes tyrosine phosphorylation of mediators of signal transduction that contain $\mathrm{SH} 2$ domains. Association with endothelial cell proliferation. J. Biol. Chem. 270:6729-6733.

36. Ziche, M., L. Morbidelli, R. Choudhuri, H.T. Zhang, S. Donnini, H.J. Granger, and R. Bicknell. 1997. Nitric oxide synthase lies downstream from vascular endothelial growth factor-induced but not basic fibroblast growth factor-induced angiogenesis. J. Clin. Invest. 99:2625-2634.

37. Andrade, S.P., I.R. Hart, and P.J. Piper. 1992. Inhibitors of nitric oxide synthase selectively reduce flow in tumor-associated neovasculature. $\mathrm{Br} . J$. Pharmacol. 107:1092-1095.

38. Konturek, S.J., T. Brzozowski, J. Majka, J. Pytko-Polonczyk, and J. Sta- chura. 1993. Inhibition of nitric oxide synthase delays healing of chronic gastric ulcers. Eur. J. Pharmacol. 239:215-217.

39. Goto, F., K. Goto, K. Weindel, and J. Folkman. 1993. Synergistic effects of vascular endothelial growth factor and basic fibroblast growth factor on the proliferation and cord formation of bovine capillary endothelial cells within collagen gels. Lab. Invest. 69:508-517.

40. Montesano, R., and L. Orci. 1985. Tumor-promoting phorbol esters induce angiogenesis in vitro. Cell. 42:469-477.

41. Sessa, W.C. 1994. The nitric oxide synthase family of proteins. J. Vasc. Res. 31:131-143.

42. Kanno, K., Y. Hirata, T. Imai, M. Iwashina, and F. Marumo. 1994. Regulation of inducible nitric oxide synthase gene by interleukin-1 beta in rat vascular endothelial cells. Am. J. Physiol. 267:H2318-H2324.

43. Zeng, G., and M.J. Quon. 1996. Insulin-stimulated production of nitric oxide is inhibited by wortmannin. Direct measurement in vascular endothelial cells. J. Clin. Invest. 98:894-898.

44. Tsukahara, H., D.V. Gordienko, B. Tonshoff, M.C. Gelato, and M.S Goligorsky. 1994. Direct demonstration of insulin-like growth factor-I-induced nitric oxide production by endothelial cells. Kidney Int. 45:598-604.

45. Ayajiki, K., M. Kindermann, M. Hecker, I. Fleming, and R. Busse. 1996. Intracellular $\mathrm{pH}$ and tyrosine phosphorylation but not calcium determine shear stress-induced nitric oxide production in native endothelial cells. Circ. Res. 78 $750-758$.

46. Inoue, N., R.C. Venema, H.S. Sayegh, Y. Ohara, T.J. Murphy, and D.G. Harrison. 1995. Molecular regulation of the bovine endothelial cell nitric oxide synthase by transforming growth factor-beta 1. Arterioscler. Thromb. Vasc. Biol. 15:1255-1261.

47. Hewett, P.W., and J.C. Murray. 1996. Coexpression of flt-1, flt-4 and KDR in freshly isolated and cultured human endothelial cells. Biochem. Biophys. Res. Commun. 221:697-702.

48. Barleon, B., S. Hauser, C. Schollmann, K. Weindel, D. Marme, A. Yayon, and H.A. Weich. 1994. Differential expression of the two VEGF receptors flt and KDR in placenta and vascular endothelial cells. J. Cell. Biochem. 54: $56-66$.

49. Pawson, T. 1988. Non-catalytic domains of cytoplasmic protein-tyrosine kinases: regulatory elements in signal transduction. Oncogene. 3:491-495.

50. Waltenberger, J., L. Claesson-Welsh, A. Siegbahn, M. Shibuya, and C.H. Heldin. 1994. Different signal transduction properties of KDR and Flt1, two receptors for vascular endothelial growth factor. J. Biol. Chem. 269:2698823695.

51. Johnson, G.L., and R.R. Vaillanncourt. 1994. Sequential protein kinase reactions controlling cell growth and differentiation. Curr. Opin. Cell Biol. 6: 230-238.

52. Berridge, M.J., and R.F. Irvine. 1989. Inositol phosphates and cell signalling. Nature. 341:197-205.

53. Franke, T.F., D.R. Kaplan, and L.C. Cantley. 1997. PI3K: downstream AKTion blocks apoptosis. Cell. 88:435-437.

54. Carpenter, C.L., and L.C. Cantley. 1996. Phosphoinositide kinases. Curr. Opin. Cell Biol. 8:153-158.

55. Marczin, N., A. Papapetropoulos, and J.D. Catravas. 1993. Tyrosine kinase inhibitors suppress endotoxin- and IL-1 beta-induced NO synthesis in aortic smooth muscle cells. Am. J. Physiol. 265:H1014-H1018.

56. Muller, J.M., M.J. Davis, and W.M. Chilian. 1996. Coronary arteriolar flow-induced vasodilation signals through tyrosine kinase. Am. J. Physiol. 270: H1878-H1884.

57. Oikawa, T., H. Ashino, M. Shimamura, M. Hasegawa, I. Morita, S. Murota, M. Ishizuka, and T. Takeuchi. 1993. Inhibition of angiogenesis by erbstatin, an inhibitor of tyrosine kinase. J. Antibiot. (Tokyo). 46:785-790.

58. Fleming, I., B. Fisslthaler, and R. Busse. 1995. Calcium signaling in endothelial cells involves activation of tyrosine kinases and leads to activation of mitogen-activated protein kinases. Circ. Res. 76:522-529.

59. Abedi, H., and I. Zachary. 1997. Vascular endothelial growth factor stimulates tyrosine phosphorylation and recruitment to new focal adhesions of focal adhesion kinase and paxillin in endothelial cells. J. Biol. Chem. 272:1544215451.

60. Derman, M.P., A. Toker, J.H. Hartwig, K. Spokes, J.R. Falck, C.-S. Chen, L.C. Cantley, and L.G. Cantley. 1997. The lipid products of phosphoinositide 3-kinase increase cell motility through protein kinase C. J. Biol. Chem. 272:6465-6470.

61. Oikawa, T., and M. Shimamura. 1996. Potent inhibition of angiogenesis by wortmannin, a fungal metabolite. Eur. J. Pharmacol. 318:93-96.

62. Sessa, W.C., G. Garcia-Cardena, J. Liu, A. Keh, J.S. Pollock, J. Bradley, S. Thiru, I.M. Braverman, and K.M. Desai. 1995. The Golgi association of endothelial nitric oxide synthase is necessary for the efficient synthesis of nitric oxide. J. Biol. Chem. 270:17641-17644.

63. Liu, J., G. Garcia-Cardena, and W.C. Sessa. 1996. Palmitoylation of endothelial nitric oxide synthase is necessary for optimal stimulated release of nitric oxide: implications for caveolae localization. Biochemistry. 35:13277-13281.

64. Carpenter, C.L., and L.C. Cantley. 1996. Phosphoinositide 3-kinase and the regulation of cell growth. Biochim. Biophys. Acta. 1288:M11-M16. 